This report has been corrected and republished. Below is the republished report. Please click here to view the detailed changes to the report.

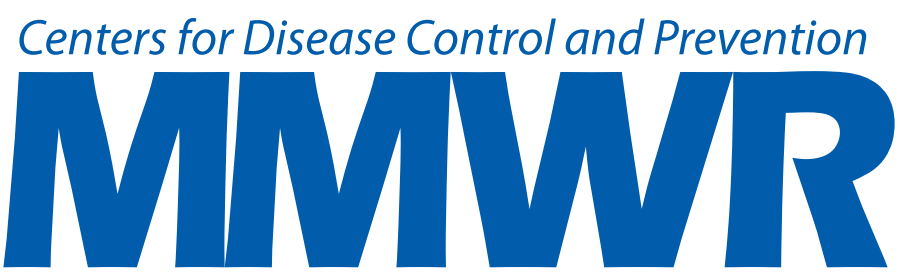

Morbidity and Mortality Weekly Report

Weekly / Vol. 68 / No. 53

January 17,2020

\title{
Associations Among School Absenteeism, Gastrointestinal and Respiratory Illness, and Income — United States, 2010-2016
}

\author{
David Berendes, $\mathrm{PhD}^{1}$; Ashley Andujar, MHSA ${ }^{1}$; Lisa C. Barrios, $\mathrm{DrPH}^{2}$; Vincent Hill, $\mathrm{PhD}^{1}$
}

Control of communicable diseases in children, including respiratory and diarrheal illnesses that affect U.S. school-aged children, might require public health preventive efforts both in the home and at school, a primary setting for transmission. National Health Interview Survey (NHIS) data on school absenteeism and gastrointestinal and respiratory illnesses in the United States during 2010-2016 were analyzed to examine their associations with income. Prevalence of gastrointestinal and respiratory illnesses (queried for the 2 weeks preceding the survey) increased as income decreased. The likelihood of missing any school days during the past year decreased with reduced income. However, among children who missed school, those from low-income households missed more days of school than did children from higher income households. Although the reason for absenteeism cannot be ascertained from this analysis, these data underscore the importance of preventive measures (e.g. hand hygiene promotion and education) and the opportunity for both homes and schools to serve as important points for implementation of public health preventive measures, including improved hand hygiene practices.

Data from the 2010-2016 NHIS (1) were obtained from IPUMS Health Surveys (https://nhis.ipums.org/nhis) and analyzed. NHIS is an annual, national household survey on the health of the civilian noninstitutionalized U.S. population, administered continually throughout the year. Family income data were linked to information about the school-aged child (5-17 years) with regard to 1) any school absenteeism in the last year, 2) number of days (reported as an integer) absent in the last year, and 3) gastrointestinal illness or respiratory illness (occurrence of a cold) during the 2 weeks preceding the interview. NHIS-imputed income files were used to present estimates by income brackets and by whether the family lived at or above the federal poverty level.* The

\footnotetext{
*The federal poverty level represents an indicator used to define the boundary for those eligible for federal aid. It is defined by the U.S. Department of Health and Human Services annually each January to adjust for inflation and is proportional to the size of the household (e.g., by 2018 guidelines, a two-person household with an income of $\$ 15,500$ would be below the poverty level, but a single-person household with the same income would not).
}

statistical software R (version 3.4.3, R Foundation for Statistical Computing) was used account for the complex sample design and weighting of the survey and compare school absenteeism, illness, and income using linear and logistic regression models, unadjusted and adjusted for age and sex of the child and year of survey. P-values $<0.05$ were considered statistically significant.

A total of 61,482 (9.6\%) households selected for the NHIS were sampled for the child-specific questionnaire and provided data about their school-age child's health and days of school missed. Households varied across income categories, with $30 \%$ earning $<\$ 35,000$ per year and $21 \%$ below the federal poverty level (Table 1). Sixty-nine percent of children missed $\geq 1$ day of school in the previous year, and approximately $15 \%$ missed $\geq 6$ days (mean $=3.24$ days per child). The prevalence of gastrointestinal and respiratory illness in the past 2 weeks was $5 \%$ and $13 \%$, respectively.

Reported school absence during the previous school year and reported respiratory or gastrointestinal illness during the previous 2 weeks were categorized by family income (Table 2). Compared with children in each of the other income categories, children in the lowest income bracket households (earning $<\$ 35,000$ per year) had a lower likelihood of missing school during the previous year (65\% versus $67 \%-73 \%)$ and higher prevalence of gastrointestinal illness $(6 \%$ versus $4 \%-5 \%)$ and respiratory illness (14\% versus $12 \%-13 \%)$ in the previous 2 weeks. Adjusting for age, sex, and year of survey, children in the lowest income bracket were 3\%-12\% (95\% confidence intervals [CIs] ranged from 1\%-14\%) less likely to miss school, but $18 \%-31 \%$ (95\% CIs ranged from $2 \%-39 \%)$ more likely to have had a recent gastrointestinal illness. Children in the lowest income bracket were also $6 \%-15 \%$ more likely to have had a respiratory illness, although comparisons with the $\$ 50,000-\$ 74,999$ and $>\$ 100,000$ income brackets were not statistically different.

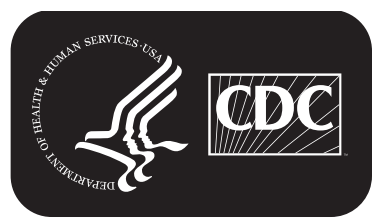

U.S. Department of Health and Human Services Centers for Disease Control and Prevention 
Results were similar when comparing children living below the federal poverty level with those at or above it. Children living below the poverty level were significantly less likely to have missed school during the past year $(65 \%$ versus $71 \%)$ and also significantly more likely to have had a gastrointestinal illness (6\% versus $5 \%)$ or respiratory illness $(14 \%$ versus $13 \%)$ in the preceding 2 weeks (Table 2). Specifically, children living below the poverty level were $9 \%(95 \% \mathrm{CI}=7 \%-11 \%)$ less likely to have missed a day of school during the last year but were $23 \%$ $(95 \% \mathrm{CI}=14 \%-31 \%)$ more likely to have had a gastrointestinal illness during the 2 weeks preceding the survey. The difference in respiratory illness between children below versus those at or above the federal poverty level was similar to results by income category (5\%) but was not statistically different.

Among children whose parents or guardian reported respiratory or gastrointestinal illness during the preceding 2 weeks, the percentage who missed any school during the last year increased with increasing income level. Among children who had gastrointestinal illness, $84.2 \%$ (family income $<\$ 35,000$ ), $84.3 \%(\$ 35,000-\$ 49,999), 88.1 \%(\$ 50,000-\$ 74,999)$, $86.2 \%(\$ 75,000-\$ 99,999)$, and $89.4 \%(\geq \$ 100,000)$ missed school in the past year. Similarly, $83.1 \%$ of children living below the poverty level with gastrointestinal illness missed school, compared with $87.4 \%$ of those living at or above the poverty level. Among children in the household income brackets listed above who had a respiratory illness during the preceding 2 weeks, $78.7 \%, 80.3 \%, 79.2 \%, 82.8 \%$, and $83.7 \%$, respectively, missed school, and $78.3 \%$ of children living in households below the federal poverty level missed school compared with $81.5 \%$ of those living at or above the poverty level. Differences for both gastrointestinal and respiratory illnesses were significant in final model risk ratios when grouped by federal poverty level, but not for all individual income categories.

When analyzed by the number of days missed in the last year, children in the lowest income bracket $(<\$ 35,000)$ missed a mean of 0.5-0.8 more days compared with children in other income brackets (Table 2). Among only those children who missed $\geq 1$ school day, the differences were larger (mean $=0.8-2.1$ more days). Similarly, overall, children living below the federal poverty level missed an average of 0.7 more days of school per year than did children in higher income households; among only those who missed $\geq 1$ day of school, the mean difference increased to 1.4 days.

\section{Discussion}

Compared with children from higher income households, those from lower income households were more likely to have had a gastrointestinal or respiratory illness during the 2 weeks preceding the survey. Although children from lower income households were less likely to have missed any days of school during the last year, those who did miss school missed more days than did children from higher income households.

The combination of increased illness prevalence and absenteeism with decreasing income status highlights the need for accessible, affordable resources and interventions at home

The MMWR series of publications is published by the Center for Surveillance, Epidemiology, and Laboratory Services, Centers for Disease Control and Prevention (CDC), U.S. Department of Health and Human Services, Atlanta, GA 30329-4027.

Suggested citation: [Author names; first three, then et al., if more than six.] [Report title]. MMWR Morb Mortal Wkly Rep 2020;69:[inclusive page numbers].

\section{Centers for Disease Control and Prevention \\ Robert R. Redfield, MD, Director}

Anne Schuchat, MD, Principal Deputy Director

Chesley L. Richards, MD, MPH, Deputy Director for Public Health Science and Surveillance

Rebecca Bunnell, PhD, MEd, Director, Office of Science

Arlene Greenspan, PhD, Acting Director, Office of Science Quality, Office of Science

Michael F. Iademarco, MD, MPH, Director, Center for Surveillance, Epidemiology, and Laboratory Services

\section{MMWR Editorial and Production Staff (Weekly)}

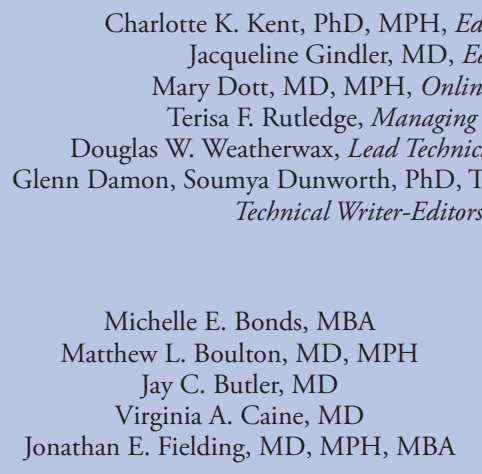

Charlotte K. Kent, PhD, MPH, Editor in Chief

Jacqueline Gindler, MD, Editor

Mary Dott, MD, MPH, Online Editor

Terisa F. Rutledge, Managing Editor

ya Dunworth, PhD, Teresa M. Hood, MS,

MMWR Editorial Board

Timothy F. Jones, MD, Chairman

David W. Fleming, MD

William E. Halperin, MD, DrPH, MPH

Jewel Mullen, MD, MPH, MPA

Jeff Niederdeppe, $\mathrm{PhD}$

Patricia Quinlisk, MD, MPH
Martha F. Boyd, Lead Visual Information Specialist Maureen A. Leahy, Julia C. Martinroe, Stephen R. Spriggs, Tong Yang, Visual Information Specialists

Quang M. Doan, MBA, Phyllis H. King,

Terraye M. Starr, Moua Yang,

Information Technology Specialists 
TABLE 1. Reported income, school absence, and gastrointestinal and respiratory illnesses among children aged 5-17 years - United States, 2010-2016*

\begin{tabular}{|c|c|c|c|c|c|c|c|c|}
\hline \multirow[b]{3}{*}{ Characteristic } & \multicolumn{8}{|c|}{ No. of respondents (\%) } \\
\hline & \multicolumn{8}{|c|}{ Year } \\
\hline & 2010 & 2011 & 2012 & 2013 & 2014 & 2015 & 2016 & Total \\
\hline Below $\mathrm{FPL}^{\dagger}$ & $1,638(20.6)$ & $1,898(20.6)$ & $2,022(20.8)$ & $1,923(21.2)$ & $1,986(21.8)$ & $1,680(19.8)$ & $1,230(18.7)$ & $12,386(20.5)$ \\
\hline \multicolumn{9}{|l|}{ Annual income } \\
\hline$<\$ 34,999$ & $2,757(31.6)$ & $3,132(31.5)$ & $3,296(31.1)$ & $3,091(30.5)$ & $3,112(30.4)$ & $2,674(28.3)$ & $2,041(27.1)$ & $20,103(30.1)$ \\
\hline$\$ 35,000-\$ 49,999$ & $1,092(12.8)$ & $1,296(13.8)$ & $1,240(13.1)$ & $1,264(12.5)$ & $1,277(12.5)$ & $1,149(12.7)$ & $927(11.8)$ & $8,245(12.7)$ \\
\hline$\$ 50,000-\$ 74,999$ & $1,382(17.9)$ & $1,503(17.1)$ & $1,568(16.7)$ & $1,512(17.1)$ & $1,587(16.5)$ & $1,529(16.8)$ & $1,330(16.2)$ & $10,411(16.9)$ \\
\hline$\$ 75,000-\$ 99,999$ & $937(13.0)$ & $1,047(12.6)$ & $1,192(13.5)$ & $1,117(13.1)$ & $1,226(12.6)$ & $1,058(12.6)$ & $1,093(13.1)$ & 7,670 (12.9) \\
\hline$\geq \$ 100,000$ & $1,701(24.7)$ & $1,942(25.1)$ & $2,056(25.6)$ & $2,141(26.7)$ & $2,348(28.0)$ & $2,323(29.6)$ & $2,543(31.9)$ & $15,054(27.4)$ \\
\hline \multicolumn{9}{|c|}{ School days absent during previous year ${ }^{\S}$} \\
\hline 0 & $2,275(27.0)$ & $2,722(28.8)$ & $3,230(34.0)$ & $2,849(29.9)$ & $3,099(32.1)$ & $2,700(29.9)$ & $2,410(32.7)$ & $19,285(30.6)$ \\
\hline Any & $5,594(73.0)$ & $6,197(71.2)$ & $6,122(66.0)$ & $6,275(70.1)$ & $6,452(67.9)$ & $6,033(70.1)$ & $5,524(67.3)$ & $42,197(69.4)$ \\
\hline $1-2$ & $2,150(28.0)$ & $2,524(29.8)$ & $2,725(29.5)$ & $2,627(29.9)$ & $2,779(29.7)$ & $2,553(30.4)$ & $2,364(30.1)$ & $17,722(29.6)$ \\
\hline $3-5$ & $2,136(27.7)$ & $2,365(26.6)$ & $2,207(24.0)$ & $2,353(26.3)$ & $2,421(26.0)$ & $2,157(25.2)$ & $2,005(23.7)$ & $15,644(25.6)$ \\
\hline $6-10$ & 857 (11.4) & $874(10.1)$ & $811(8.7)$ & $866(9.5)$ & $866(8.6)$ & $900(10.3)$ & $788(9.3)$ & $5,962(9.7)$ \\
\hline$\geq 11$ & $451(5.9)$ & $434(4.6)$ & $379(3.8)$ & $429(4.5)$ & $386(3.6)$ & $423(4.2)$ & $367(4.3)$ & $2,869(4.4)$ \\
\hline Mean days absent (SD) & $3.73(7.61)$ & $3.35(6.65)$ & $2.96(6.54)$ & $3.27(6.18)$ & $3.00(6.33)$ & $3.24(6.09)$ & $3.10(6.05)$ & $3.24(6.52)$ \\
\hline \multicolumn{9}{|c|}{ Illness during past 2 weeks } \\
\hline Gastrointestinal & $413(5.8)$ & $470(5.6)$ & $399(4.5)$ & $437(5.1)$ & $476(5.0)$ & $392(4.0)$ & $371(4.6)$ & $2,958(5.0)$ \\
\hline Respiratory & $1,041(13.1)$ & $1,255(14.5)$ & $995(10.8)$ & $1,299(14.1)$ & $1,210(12.9)$ & $1,111(12.2)$ & $997(12.2)$ & $7,908(12.8)$ \\
\hline
\end{tabular}

Abbreviations: $\mathrm{SD}=$ standard deviation; $\mathrm{FPL}=$ federal poverty level.

* Data are presented as the unweighted number of respondents $(\mathrm{N})$ and weighted percentage $(\%)$, with the exception of the mean number of school days absent (weighted mean and standard deviation presented).

† FPL represents an indicator used to define the boundary for those eligible for federal aid; FPL is defined by the U.S. Department of Health and Human Services annually each January to adjust for inflation and is proportional to the size of the household.

$\S$ Parents or caregivers reported the number of days missed as integers, which were then categorized into the categories shown.

and school. Multiple barriers faced by children in low-income households could explain these findings, including lack of access to preventive health care (2). Although targeted social distancing, such as a requirement for absence from school might be an effective recommended course of action to protect public health $(3,4)$, low-income parents might not have the opportunities (e.g., paid sick leave from work) to be able to implement this. These circumstances might affect both their children's ability to stay home from school and health-seeking behaviors (5). In the long-term, longer periods of absenteeism could be associated with adverse educational outcomes (G).

The findings in this report are subject to at least two limitations. First, although NHIS collects health and school absence data generalizable to the civilian noninstitutionalized U.S. population, the reasons for school absence are not collected. Second, both health and school absence data are parentally reported, making them subject to recall bias, and the data are not consistent in their respective recall timelines (preceding 2 weeks versus preceding year). However, recall of self-reported illness and school absenteeism is likely to be more accurate for the recent past (7); thus, the association between reporting of recent illness and school absenteeism is likely to be strengthened. In addition, subgroup estimates for illnesses, though small in difference (one percentage point) had relative standard errors $<30$.
From a public health perspective, these findings highlight a need for resources for, and attention to, preventive measures to keep children in school. Beyond practices in the home, schools have opportunities to serve as settings for preventing transmission of communicable diseases. Some school-based programs promoting handwashing, and more generally hand hygiene, have been found to be effective in reducing gastrointestinal and respiratory illnesses and associated absenteeism (8). Research suggests that peer support and provision of soap can increase handwashing and reduce absenteeism related to both gastrointestinal and respiratory illnesses (9). However, further study of sustained, communitybased encouragement of proper hand hygiene practices as effective, low-cost means of preventing such illnesses is needed. Ongoing health promotion activities in schools, in addition to the home, can increase awareness and understanding of handwashing with soap as an effective and affordable way to prevent transmission of infectious diseases. Increased public awareness of the importance of hand hygiene, as promoted by Global Handwashing Day (observed each year on October 15), is important to promoting public health and reducing the transmission of illness.

Corresponding author: David Berendes, dberendes@cdc.gov, 404-718-5853.

${ }^{1}$ Division of Foodborne, Waterborne, and Environmental Diseases, CDC; ${ }^{2}$ Division of Adolescent and School Health, CDC.

All authors have completed and submitted the ICMJE form for disclosure of potential conflicts of interest. No potential conflicts of interest were disclosed. 
TABLE 2. Reported absence and illness by income and poverty status among children aged 5-17 years and percentage of respondents reporting school absence and illness among children aged 5-17 years, by income and federal poverty level (FPL) status* - National Health Interview Survey, 2010-2016, United States, 2010-2016

\begin{tabular}{|c|c|c|c|c|c|c|c|}
\hline \multirow[b]{3}{*}{ Characteristic } & \multicolumn{7}{|c|}{ No. of respondents (\%) } \\
\hline & \multicolumn{5}{|c|}{ Income } & \multicolumn{2}{|c|}{ Poverty status } \\
\hline & $<\$ 35,000$ & $\$ 35,000-\$ 49,999$ & $\$ 50,000-\$ 74,999$ & $\$ 75,000-\$ 99,999$ & $\geq \$ 100,000$ & Below FPL & At or above FPL \\
\hline \multicolumn{8}{|c|}{ School days absent } \\
\hline 0 & $7,105(34.6)$ & $2,741(32.6)$ & $3,180(30.4)$ & $2,154(27.8)$ & $4,105(26.8)$ & 4,423 (34.9) & $14,862(29.5)$ \\
\hline Any & $12,998(65.4)$ & $5,504(67.4)$ & $7,230(69.6)$ & $5,516(72.2)$ & $10,949(73.2)$ & $7,953(65.1)$ & $34,244(70.5)$ \\
\hline $\mathrm{PR}(95 \% \mathrm{Cl})$ & Referent & 1.03 (1.01 to 1.05$)$ & 1.06 (1.04 to 1.09$)$ & $1.10(1.08$ to 1.13$)$ & $1.12(1.10$ to 1.14$)$ & Referent & 1.08 (1.06 to 1.10$)$ \\
\hline $\mathrm{aPR}^{\S}(95 \% \mathrm{Cl})$ & Referent & 1.03 (1.01 to 1.06$)$ & 1.07 (1.04 to 1.09$)$ & 1.11 (1.08 to 1.13$)$ & $1.12(1.10$ to 1.14$)$ & Referent & $1.09(1.07$ to 1.11$)$ \\
\hline $1-2$ & $4,774(24.0)$ & $2,231(28.2)$ & $3,052(29.7)$ & $2,408(31.8)$ & $5,257(35.4)$ & $2,864(23.6)$ & $14,858(31.2)$ \\
\hline $3-5$ & $4,779(24.3)$ & $2,049(24.5)$ & $2,715(26.2)$ & $2,122(27.6)$ & $3,979(26.4)$ & $2,943(24.4)$ & $12,701(26.0)$ \\
\hline $6-10$ & $2,154(10.7)$ & $796(9.8)$ & $1,043(10.0)$ & $723(9.6)$ & 1,246 (8.4) & $1,328(10.5)$ & $4,634(9.5)$ \\
\hline$\geq 11$ & $1,290(6.4)$ & $428(4.9)$ & $420(3.8)$ & $264(3.2)$ & $467(3.0)$ & $818(6.5)$ & $2,051(3.9)$ \\
\hline Mean (SD) all & $3.73(8.27)$ & $3.29(6.60)$ & $3.05(5.36)$ & $2.95(4.43)$ & $2.91(5.68)$ & $3.76(8.61)$ & $3.10(5.85)$ \\
\hline Est ${ }^{\mathbb{I}}(95 \% \mathrm{Cl})$ & Referent & $-0.44(-0.67$ to -0.21$)$ & $-0.69(-0.89$ to -0.48$)$ & $-0.78(-0.99$ to -0.57$)$ & $-0.82(-1.03$ to -0.62$)$ & Referent & $-0.66(-0.88$ to -0.44$)$ \\
\hline $\mathrm{aEst}^{\S}(95 \% \mathrm{Cl})$ & Referent & $-0.46(-0.69$ to -0.22$)$ & $-0.71(-0.91$ to -0.50$)$ & $-0.80(-1.00$ to -0.59$)$ & $-0.84(-1.05$ to -0.64$)$ & Referent & $-0.69(-0.91$ to -0.47$)$ \\
\hline Mean $(S D)^{* *}$ & $5.70(9.66)$ & $4.88(7.54)$ & $4.37(5.96)$ & $4.09(4.75)$ & $3.98(6.31)$ & $5.78(10.11)$ & $4.40(6.54)$ \\
\hline Est $(95 \% \mathrm{Cl})$ & Referent & $-0.82(-1.14$ to -0.49$)$ & $-1.33(-1.61$ to -1.05$)$ & $-1.61(-1.89$ to -1.33$)$ & $-1.73(-2.01$ to -1.44$)$ & Referent & $-1.38(-1.69$ to -1.07$)$ \\
\hline $\mathrm{aEst}^{\S}(95 \% \mathrm{Cl})$ & Referent & $-0.84(-1.17$ to -0.52$)$ & $-1.36(-1.65$ to -1.08$)$ & $-1.66(-1.94$ to -1.38$)$ & $-1.77(-2.05$ to -1.49$)$ & Referent & $-1.44(-1.75$ to -1.12$)$ \\
\hline \multicolumn{8}{|c|}{ Illness during past 2 weeks } \\
\hline Gastrointestinal & $1,128(6.0)$ & $390(4.9)$ & $508(4.8)$ & $331(4.6)$ & $601(4.1)$ & $733(6.1)$ & $2,225(4.7)$ \\
\hline PR $(95 \% \mathrm{Cl})$ & Referent & 0.82 (0.69 to 0.97$)$ & 0.81 (0.71 to 0.92$)$ & $0.77(0.65$ to 0.90$)$ & $0.68(0.59$ to 0.77$)$ & Referent & $0.76(0.68$ to 0.84$)$ \\
\hline $\mathrm{aPR}^{\S}(95 \% \mathrm{Cl})$ & Referent & 0.82 (0.69 to 0.98 ) & 0.81 (0.72 to 0.92$)$ & 0.78 (0.66 to 0.91$)$ & $0.69(0.61$ to 0.79$)$ & Referent & 0.77 (0.69 to 0.86$)$ \\
\hline Respiratory & $2,736(13.7)$ & $1,045(12.4)$ & $1,316(12.8)$ & $919(11.5)$ & $1,892(12.7)$ & $1,687(13.5)$ & $6,221(12.7)$ \\
\hline $\mathrm{PR}(95 \% \mathrm{Cl})$ & Referent & 0.90 (0.82 to 0.98$)$ & 0.93 (0.86 to 1.01$)$ & 0.84 (0.76 to 0.93$)$ & 0.93 (0.86 to 1.00$)$ & Referent & 0.94 (0.88 to 1.00$)$ \\
\hline $\mathrm{aPR}^{\S}(95 \% \mathrm{Cl})$ & Referent & 0.91 (0.83 to 0.99$)$ & $0.94(0.86$ to 1.02$)$ & 0.85 (0.77 to 0.94$)$ & 0.94 (0.88 to 1.02$)$ & Referent & $0.95(0.89$ to 1.02$)$ \\
\hline
\end{tabular}

Abbreviations: aEst = adjusted estimate (from linear regression); aPR = adjusted prevalence ratio; $\mathrm{Cl}=$ confidence interval; Est $=$ estimate (from linear regression); $\mathrm{FPL}=$ federal poverty level; $\mathrm{PR}=$ prevalence ratio; $\mathrm{SD}=$ standard deviation.

* FPL represents an indicator used to define the boundary for those eligible for federal aid; FPL is defined by the U.S. Department of Health and Human Services annually each January to adjust for inflation and is proportional to the size of the household. Because the poverty line data includes both income and number of household members, there were more missing values for poverty level; therefore, the numbers in the below FPL and at or above FPL groups do not sum to the number in all income groups.

† Data are presented as the unweighted number of respondents $(\mathrm{N})$ and weighted percentage (\%), with the exception of the mean number of school days absent (weighted mean and standard deviation presented).

$\S$ Adjusted for age and sex of child, as well as year of data collection.

" Estimated difference from reference.

** Among those missing $\geq 1$ school day only.

\section{Summary}

What is already known about this topic?

Gastrointestinal and respiratory infections are important illnesses that affect U.S. school-aged children. Schools can serve as primary settings of transmission.

What is added by this report?

During 2010-2016, parents of children from low-income households were more likely to report recent childhood gastrointestinal and respiratory illnesses than were higher income parents. Although parents of children from low-income households were less likely to report missing any school, when these children did miss school, they tended to miss more school days, on average.

What are the implications for public health practice?

Further studies to explore what factors underlie these associations with income are needed. In the meantime, public health partners could expand efforts to prevent gastrointestinal and respiratory illnesses in schools, especially low-cost measures such as promoting hand hygiene education.

\section{References}

1. National Center for Health Statistics; CDC. NHIS - National Health Interview Survey. Atlanta, GA: US Department of Health and Human Services, CDC; 2019. https://www.cdc.gov/nchs/nhis/index.htm

2. Morsy L, Rothstein R. Five social disadvantages that depress student performance: why schools alone can't close achievement gaps. Washington, DC: Economic Policy Institute, 2015 https://www.epi.org/files/ pdf/86987.pdf

3. Glass RJ, Glass LM, Beyeler WE, Min HJ. Targeted social distancing design for pandemic influenza. Emerg Infect Dis 2006;12:1671-81. https://doi.org/10.3201/eid1211.060255

4. Qualls N, Levitt A, Kanade N, et al.; CDC Community Mitigation Guidelines Work Group. Community mitigation guidelines to prevent pandemic influenza-United States, 2017. MMWR Recomm Rep 2017;66(No. RR-1). https://doi.org/10.15585/mmwr.rr6601a1

5. DeRigne L, Stoddard-Dare P, Quinn L. Workers without paid sick leave less likely to take time off for illness or injury compared to those with paid sick leave. Health Aff (Millwood) 2016;35:520-7. https://doi. org/10.1377/hlthaff.2015.0965

6. Balfanz R, Byrnes V. The importance of being in school: a report on absenteeism in the nation's public schools. Baltimore, MD: Johns Hopkins University Center for Social Organization of Schools; 2012. http://new.everylgraduates.org/wp-content/uploads/2012/05/ FINALChronicAbsenteeismReport_May16.pdf 
7. Arnold BF, Galiani S, Ram PK, et al. Optimal recall period for caregiverreported illness in risk factor and intervention studies: a multicountry study. Am J Epidemiol 2013;177:361-70. https://doi.org/10.1093/aje/kws281

8. Wang Z, Lapinski M, Quilliam E, Jaykus LA, Fraser A. The effect of hand-hygiene interventions on infectious disease-associated absenteeism in elementary schools: A systematic literature review. Am J Infect Control 2017;45:682-9. https://doi.org/10.1016/j.ajic.2017.01.018
9. Bowen A, Ma H, Ou J, et al. A cluster-randomized controlled trial evaluating the effect of a handwashing-promotion program in Chinese primary schools. Am J Trop Med Hyg 2007;76:1166-73. https://doi. org/10.4269/ajtmh.2007.76.1166 


The Morbidity and Mortality Weekly Report (MMWR) Series is prepared by the Centers for Disease Control and Prevention (CDC) and is available free of charge in electronic format. To receive an electronic copy each week, visit MMWR at https://www.cdc.gov/mmwr/index.html.

Readers who have difficulty accessing this PDF file may access the HTML file at $h t t p s: / / w w w . c d c . g o v / m m w r / i n d e x 2019$. html. Address all inquiries about the MMWR Series, including material to be considered for publication, to Executive Editor, MMWR Series, Mailstop E-90, CDC, 1600 Clifton Rd., N.E., Atlanta, GA 30329-4027 or to mmwrq@cdc.gov.

All material in the MMWR Series is in the public domain and may be used and reprinted without permission; citation as to source, however, is appreciated. MMWR and Morbidity and Mortality Weekly Report are service marks of the U.S. Department of Health and Human Services.

Use of trade names and commercial sources is for identification only and does not imply endorsement by the U.S. Department of Health and Human Services.

References to non-CDC sites on the Internet are provided as a service to $M M W R$ readers and do not constitute or imply endorsement of these organizations or their programs by CDC or the U.S. Department of Health and Human Services. CDC is not responsible for the content of these sites. URL addresses listed in $M M W R$ were current as of the date of publication.

ISSN: 0149-2195 (Print) 